\title{
A formação do homem no Emílio de Rousseau
}

Wilson Alves de Paiva

Universidade Federal de Goiás

\section{Resumo}

Desenvolvida inicialmente como um capítulo da dissertação de mestrado, a temática deste artigo diz respeito à dimensão humana que o projeto educacional rousseauniano procura desenvolver. Mesmo objetivando a formação do cidadão (tese que a dissertação procura defender), o plano político e pedagógico de Rousseau busca englobar o desenvolvimento dos talentos naturais como próprios da natureza humana. 0 artigo tem como fonte básica o livro Emílio ou da educação, de autoria do filósofo genebrino Jean-Jacques Rousseau. Apoiado também nos demais escritos, compilados na obra Oeuvres complètes, o texto procura resgatar a importância dessa temática para a educação da atualidade, bem como a importância do pensamento de Rousseau para a discussão em torno dos objetivos da formação do homem moderno e dos princípios que permeiam os processos formacionais. Realça que o projeto de humanização presente na obra de Rousseau é de caráter político e, portanto, contribui para que o processo educacional e os modos de inserção e participação do homem no meio social sejam repensados em nossos dias. No entanto, a ação política bem como a pedagógica devem ser empreendidas no sentido de se redimensionar as potencialidades naturais do homem de maneira que a natureza humana não seja degenerada, ignorada ou até mesmo coisificada. Construir sentidos para a existência humana e pensar a melhor maneira de participação no meio social devem, nesse sentido, ser a principal preocupação de todo e qualquer projeto político-educacional.

\section{Palavras-chave}

Rousseau - Emílio - Formação do homem - Educação moderna. 


\title{
The formation of man in Rousseau's Émile
}

Wilson Alves de Paiva

Universidade Federal de Goiás

\begin{abstract}
Initially approached as a chapter for a Master's Thesis, the theme of this article concerns the human dimension which Rousseau's educational project seeks to develop. While aiming at the formation of the citizen (an argument developed in the thesis), Rousseau's political and pedagogical plan attempts to include the development of natural talents as proper to the human nature. The article has as its basic source the Geneva-born philosopher's Émile: or, on Education. Also based on his other works compiled under his Oeuvres Complètes, the text seeks to recover the current importance of this theme for education, as well as the relevance of Rousseau's thought for the discussion of the objectives of the formation of modern man and of the principles underlying the formation processes. It emphasizes that the humanization project present in Rousseau's work is of a political nature and, therefore, that it contributes to rethink in our days the educational process and the modes of insertion and participation of man in the social sphere. However, the political action, as well as the pedagogical, must be carried out with the purpose of redimensioning man's natural potentials so that the human nature is not degenerated, ignored, or even "thingified". In this sense, to construct meanings for human existence and to think the best way of participation in the social sphere should be the main concerns of each and every political-educational project.
\end{abstract}

\section{Keywords}

Rousseau - Émile - Formation of man - Modern education.

\footnotetext{
Contact:

Wilson Alves de Paiva

Rua 12A, n. 40 - Setor Oeste

75380-000 - Trindade - GO

e-mail: wap@usp.br
} 
En efeto, rematado ya su juicio, vino a dar en el más extraño pensamiento que jamás dio loco en el mundo, y fue que le pareció convenible y necesario, así para el aumento de su honra como para el servicio de su república, hacerse caballero andante. (Miguel de Cervantes)

"Mas faremos de Emílio um cavaleiro andante, um paladino?", questiona o preceptor diante de sua obra de formação humana. Assim como o nobre cavaleiro de La Mancha', sai de si num desvario alucinante e se lança à tarefa de salvar o mundo com sua heróica bravura, a obra de arte que sai das mãos do "cavaleiro" de Genebra "irá imiscuir-se nos negócios públicos, exibir-se como um sábio defensor das leis entre os grandes e os magistrados, junto ao príncipe, solicitador dos juízes e advogado nos tribunais?" (Rousseau, 1973, p. 280). Ou será um Crusoé solitário que após ter saído de sua ilha deserta e viajado todo o mundo, ouve de um príncipe russo que a verdadeira grandeza nesse mundo é ser dono de si mesmo ${ }^{2}$ Emílio tentará salvar o mundo ou salvará a si mesmo? Resumindo, será um homem ou será um cidadão?

0 questionamento de Jean-Jacques Rousseau é também o questionamento que se colocam aos que lêem sua obra e se perdem entre os dois ideais de formação humana concebidos pelo filósofo. Além disso, é também a grande questão que se apresenta na atualidade em face às mudanças que o último quartel do século XX passou a apresentar no cenário mundial. Fartamente discutido no Relatório Jacques Delors, a preocupação da Comissão Internacional sobre Educação para o século XXI e da grande maioria dos educadores de todo o mundo é quanto aos objetivos e às finalidades do ato educativo, diante de uma realidade na qual assistimos a uma verdadeira reificação do homem e, ao mesmo tempo, a dissolução das fronteiras pátrias bem como das identidades culturais. 0 avanço tecnológico, a financeirização da vida cotidiana e uma possível macdonaldização ${ }^{3}$ da escola e seu mundo acabam operando um esvaecimento do homem, suas identidades e seus problemas sociais. Gadotti (2004) denuncia: "Esse é um dos atrasos da nossa civilização. Avançamos muito no plano das tecnologias e pouco no que se refere ao governo do humano" (p. 229).

0 grande tratado educacional de Rousseau não é, nesse sentido, uma obra quixotesca. As questões que o mestre genebrino coloca em sua obra, por mais esdrúxulas que podem ter sido em sua época, contribuíram substancialmente para a valorização do homem e suas especificidades psicológicas no âmbito da educação moderna e servem de condimento indispensável às questões da atualidade, tanto no campo educacional como no político. Olhando nesse ângulo, Emílio não é uma mera ficção ou pura abstração literária. Pode até ser um devaneio filosófico ou mesmo um delírio de alguém que, como Cervantes, não queria apenas criticar ou satirizar os costumes e as crenças de sua época, mas repensar profundamente a existência e a formação humana.

Em vez de vaguear ao sabor de loucas aventuras, o preceptor prefere abrir o caminho das empiricidades para criar o sentido da existência e dialogar com o real a fim de estabelecer o estatuto da ação formativa: arte que encampa um plano global de construção das identidades, tanto individual como coletivas, com o intuito de propiciar a felicidade da espécie humana, ou seja, o bem-estar geral do homem. Nesse aspecto, o que o tratado rousseauniano almeja é a formação do homem: "saindo de minhas mãos, ele não será, concordo, nem magistrado, nem soldado, nem padre, será primeiramente um homem" (Rousseau, 1973, p. 15). E em resposta ao seu próprio questionamento a respeito da formação de Emílio para que seja um paladino, ele responde: "Nada sei disso". E completa afirmando: "Seu primeiro dever é para consigo mesmo" (p. 280). Perspectiva que abre

\footnotetext{
1. Trata-se de D. Quixote, principal personagem da obra de Miguel de Cervantes (1993).

2. Trata-se de Príncipe Ganitzine (Defoe, 1947)

3. Termo criado por Pablo Gentili no texto: "A MacDonaldização da escola." (Costa, 2000).
} 
um caminho novo na história da formação humana. Até então as atividades formativas e os princípios educacionais das diferentes civilizações e povos tiveram um caráter eminentemente social, cuja objetividade holista não deixava espaço para o desenvolvimento do homem como indivíduo. 0 dever dos educandos era para com as necessidades imediatas do grupo, tendo em vista a manutenção física de seu status e até mesmo de sua existência. Estendia-se também às necessidades não imediatas para a manutenção de uma teia de mitos e crenças que fortalecia a unidade do grupo, perpetuava o jogo de poder e mistificava o conhecimento. Em todos os casos, por mais positiva que tenha sido a preservação da identidade cultural, a relação que se estabelecia entre educador e educando não passava de uma transmissão hierárquica do saber institucionalizado. Mesmo o individualismo cristão ficou circunscrito à idéia de Cristandade ${ }^{4}$, e tanto o controle moral pela consciência quanto à imagem de homem livre acabaram diluídos numa prática pedagógica autoritária e dogmática que se seguiu sob os auspícios da patrística e da escolástica.

Com a Renascença, a estética da formação humana ganha realce e os ideais clássicos fornecem os contornos para que a educação seja vista como uma ação de liberação do indivíduo e realização do ideal humano. Na prática, entretanto, o humanismo renascentista não se aproximou muito da meta, até porque como diz Rousseau (1973),

[...] sendo portanto a educação uma arte, torna-se quase impossivel que alcance êxito total, porquanto a ação necessária a esse êxito não depende de ninguém. Tudo o que se pode fazer, à força de cuidados, é aproximar-se mais ou menos da meta, mas é preciso sorte para atingi-la. (p. 11)

Para o século XVIIl, “arte é qualquer método que tende a promover e aperfeiçoar um fenômeno natural, ordená-lo e fazê-lo agradável e útil" (Starobinski, 1987, p. 12). Dessa forma, o Emílio é um exemplo de obra de arte na qual o homem aparece como fenômeno natural e é desnaturado pelas instituições sociais sem, entretanto, matar-lhe a natureza humana e sufocar sua bondade. Obra que engloba os ideais renascentistas, cristãos e mesmo iluministas, mas numa perspectiva própria que valoriza o homem real, concreto, empírico e circunstancial. Emílio não será, nessa perspectiva, um marmóreo David $^{5}$ a ostentar a perfeição externa de sua aparência ou uma figura mística de traços distorcidos saída de uma das telas do maneirista El Greco $(1541-1614)^{6}$. Não carregará as luzes das telas impressionistas $^{7}$ e também não será o sujeito elidido da grande obra Las niñas, de Velásquez ${ }^{8}$, na qual tanto o representante quanto o representado desaparece em favor da pura representação. Quanto a essa análise:

Os homens do século das luzes não se contentavam por simplesmente experimentar o prazer proporcionado pelas obras de arte: Queriam avaliar as características particulares dessas obras e situá-las na perspectiva de um plano universal de desenvolvimento da humanidade. (Starobinski, 1987, p. 9)

Analisando dessa forma, Jean-Jacques é inteiramente fruto de seu século, sem ser seu facsímile. A originalidade e a diferença de seu pensamento reside no seguinte: o homem é a supre-

4. Termo utilizado para definir toda a Europa latina e norte da África e dar noção de unidade, tendo em vista que o sentido de pátria ainda não existia no período medieval.

5. Obra do grande renascentista Michelangelo (1475-1564). Abrangendo o século XV e o XVI, o Renascimento foi o movimento iniciado na Itália, fundamentado no homem como a medida de todas as coisas e no retorno à cultura greco-romana. Descartando a escolástica medieval, a filosofia renascentista propunha a valorização das virtudes da antiguidade clássica. 6. Paralelamente ao Renascimento, desenvolve em Roma, entre 1520 e 1610 aproximadamente, um movimento artístico denominado Maneirismo, cuja estilização exagerada das formas afasta suas obras do rigor clássico e as aproxima do barroco. Domenikos Theotokopoulos, mais conhecido como El Greco, foi um de seus maiores representantes.

7. Impressionismo: movimento pictórico do século XIX que expressa a realidade essencialmente como impressão de fenômenos de cor e luz.

8. Pintor espanhol cuja obra citada é fartamente analisada por Foucault (1999) como testemunho da representação do período clássico. № quadro, aparecem todas as imagens possíveis, menos a figura do rei e da rainha (Felipe IV e sua esposa) que estão sendo retratados, a não ser num pequeno espelho na parede do fundo, apenas como reflexo opaco de um mundo taxionômico. 
ma obra de arte da Natureza e a bondade é a dádiva natural que possibilita sua realização. Rousseau não se contenta em apenas admirar essa obra de arte, mas quer avaliar suas características próprias na forma que saiu das mãos do autor das coisas. Para tanto, situa o homem em duas perspectivas: a histórica, na qual o processo de degeneração o desfigurou, semelhante à estátua de Glauco que o tempo, o mar e as intempéries fizeram com que parecesse mais um animal feroz do que a um deus. Perspectiva um tanto quanto pessimista, mas que traduz a real situação de desigualdades e guerra do ser humano ao longo da história. E a outra, a possível, é a perspectiva mais propriamente rousseauniana, na qual o autor desenvolve um plano universal de desenvolvimento da humanidade. Perspectiva um tanto quanto ideal, platônica, mas cuja singularidade está no fato de que trabalha o dever-ser pela arte (educacional e política) do conserto, da reconciliação. Como a degeneração veio pelas mãos do homem, cabe a ele reconciliar-se com sua própria natureza, consigo mesmo e com o próximo. É essa a mais sublime tarefa moral que se impõe para o benefício da espécie e o progresso da humanidade. Realiza-se por meio de um amplo projeto de formação que contém um plano individual, de formação do homem em todas suas disposições naturais, e um plano coletivo de formação do homem social, isto é, do cidadão.

Há dois sentidos de homme na obra de Rousseau. 0 primeiro é o homem natural e o segundo, o homem civil. 0 homem natural, por sua vez, significa o homem primitivo, encontrado num estágio anterior à sociedade e ao plano histórico da humanidade, bem como o homem natural que vive comunitariamente entre seus semelhantes já num estágio avançado de civilidade. A bondade, a sensibilidade e o caráter reto desse espécime fazem dele um homem autêntico por apresentar todas suas potencia-lidades como indivíduo e todo seu engenho como ser no mundo, real e concreto. 0 homem civil se desdobra em burguês e cidadão. 0 burguês é o pseudocidadão, possuidor de privilégios resultantes da dominação sobre o semelhante e da usurpação da propriedade, como bem de- monstrado no segundo Discurso. 0 cidadão é o homem ideal, o ser coletivo, unidade fracionária e fruto do contrato social. 0 que chamo de homem total é a junção do homem autêntico com o cidadão, superando o burguês e todos os vícios engendrados no desvirtuamento das paixões. A superação do homem burguês se dá primeiramente pela rejeição do mundo das aparências e do disfarce, criado pela multiplicidade de sinais representativos cuja positivação legitimou uma realidade contrária à ordem natural. "Emílio é o homem da sociedade que menos sabe disfarçar" (Rousseau, 1973, p. 488). Em segundo lugar, pelo desenvolvimento da natureza do homem conforme os principios naturais por meio de um amplo projeto político (Contrato Social) que não prescinda de também uma ampla formação humana (Emílio).

0 homem total é a soma da dimensão natural e da dimensão civil ou ainda dos dois ideais rousseaunianos numa só pessoa. É assim, como o Emílio, bem preparado para viver no mundo moderno e serve de protótipo do cidadão de uma possível sociedade nos moldes do Contrato Social.

As duas dimensões são chamadas por Rousseau de ordem natural e ordem civil. Dois planos que se entrelaçam e se realizam sem primazia de uma ou de outra, mas realizações simultâneas. "Aquele que, na ordem civil, deseja conservar a primazia da natureza, não sabe o que quer" (Rousseau, 1973, p. 13). Porque não deve haver primazia de nenhuma e sim a conjugação de ambas, tanto na organização geral da sociedade quanto na formação específica do homem. São duas dimensões presentes em todo o ato formativo que acontece desde o nascimento da criança (plano individual) até sua plena constituição como cidadão (plano coletivo). Não se forma o homem e só depois o cidadão ou vice-versa, mas ambos são formados por um projeto político-educacional que vislumbra o homem total. Além disso, a formação do homem é a vocação primeira, reclamada pela natureza, como diz Rousseau (1973):

$\mathrm{Na}$ ordem natural, sendo os homens todos iguais, sua vocação comum é o estado de 
homem; e quem quer seja bem educado para esses, não pode desempenhar-se mal dos que com esse se relacionam. Que se destine meu aluno à carreira militar, à eclesiástica ou à advocacia pouco me importa. Antes da vocação dos pais, a natureza chama-o para a vida humana. Viver é o ofício que the quero ensinar. (p. 15)

Eis, pois, o plano de desenvolvimento da dimensão humana, presente no pensamento de Rousseau desde 1740 quando foi preceptor dos filhos do Sr. Jean Bonnot de Mably de cuja experiência escreveu seu Projeto para educação do Senhor de Sainte-Marie, no qual afirmou que "o objetivo que devemos nos propor na educação de um jovem é o de formar-lhe o coração, o juízo e o espírito" (Rousseau, 1994, p. 45).

A formação do coração se inicia com a educação da natureza, o primeiro mestre. Realiza-se por meio de uma intensa sondagem de si mesmo com vistas ao autoconhecimento e ao autocontrole de todas suas emoções, paixões e capacidades. Sondar o coração também pode ser revestido de um sentido de prospecção das virtudes naturais, impressas na alma pela Natureza, para ser utilizadas como guias das ações humanas. 0 amor de si, por exemplo, degenera-se em amor próprio por falta de uma ação educativa adequada. Nas palavras de Rousseau em suas Confissões (1964): "São quase sempre os primeiros sentimentos mal dirigidos que fazem com que as crianças dêem os primeiros passos para o mal" (Vol. 1, p. 52). Dirigi-los da melhor forma é agir desde a mais tenra idade, desenvolvendo sua sensibilidade mediante exercícios práticos, jogos, brincadeiras e passeios. Nos jogos noturnos, por exemplo, Emílio desenvolve suas capacidades sensitivas, o raciocínio, a criatividade e a bondade. Nesse caso, nas corridas, o jovem vencedor é convencido pelo preceptor a repartir o prêmio, um docinho, com aqueles que disputaram e não tiveram a mesma sorte. Até porque "exercer os sentidos não é somente fazer uso deles, é aprender a bem julgar por eles” (Rousseau, 1973, p.130). E assim é que a ação conjunta dos demais mestres complementa a obra de bem preparar os sentimentos, os julgamentos e a moralidade.

Como afirma Streck (2003), "Rousseau fala na compaixão como o sentimento básico a ser cultivado pelo Emílio na medida em que conhece o mundo com as desigualdades criadas pelos homens" (p. 151). Compaixão pode ser entendida de diversas maneiras, mas ontologicamente falando o termo evoca um respeito profundo por si mesmo e pelo outro no relacionamento diário com o semelhante e com as coisas (ação conjunta dos três mestres). Evoca também o que Paulo Freire (2000) chama de "ética universal do ser humano" (129-130) na construção de um mundo mais justo e igualitário. Assim, num encadeamento ideal das ações humanas, a compaixão pode gerar a solidariedade e, esta, o amor. Nesse sentido, se é como diz Gadotti (2004) que a solidariedade é uma exigência ontológica, tal reflexão combina com as palavras de Rousseau: "o amor ao gênero humano não é outra coisa em nós senão o amor à justiça” (Rousseau, 1973, p. 283).

Influenciado pelo Renascimento, o pensamento filosófico do século XVIll gerou um conceito científico de arte que prima mais para o artifício racional do que para uma emanação pura da natureza. Ou seja, viam a arte

\section{[...] como aquele produto da atividade huma- na que, obedecendo a determinados principi- os, tem por fim produzir artificialmente os múltiplos aspectos de uma só beleza univer- sal, apanágio das coisas naturais. (Nunes, 2000, p. 10)}

Nos escritos de Rousseau, o gênero humano pode ser entendido como a mais bela obra de arte da Natureza porque nele estão as marcas universais do Belo. Toda a ação formativa deve ter em vista realçar essas marcas e trabalhar negativamente no sentido de evitar sua deterioração:

Meu principal objetivo, ensinando-lhe a sentir e amar o belo em todos os gêneros é de nele fixar suas afeições e seus gostos, e im- 
pedir que suas tendências naturais se alterem e que ele busque um dia, em sua riqueza, os meios de ser feliz, que deve encontrar perto dele. (Rousseau, 1973, p. 400)

Se nascemos sensíveis e somos logo molestados (affectés) por tudo que nos cerca (Rousseau, 1973), a tarefa de cultivar a ordem natural e formar o homem conforme os atributos da natureza começa com o nascimento e se prolonga por toda a vida. A família, principalmente na pessoa dos pais, tem a responsabilidade de bem conduzir esse relacionamento inicial com o meio. Para tanto, basta observar a regra da natureza e o caminho que ela indica. Afinal, a dor, a dentição, o enrijecimento dos músculos, as necessidades vitais, as intempéries climáticas e os diversos outros recursos naturais proporcionam o desenvolvimento da sensação como o primeiro material do conhecimento.

Quereis que conserve sua forma original? Conservai a partir do instante em que vem ao mundo. Logo ao nascer apropriai-vos dele, não o largueis antes que seja homem: nada conseguireis sem isso. Assim como a verdadeira ama é a mãe, o verdadeiro preceptor é o pai. (Rousseau, 1973, p. 24)

Esse e outros excertos revelam uma concepção de educação como um ato social que não deve ser negligenciado por ninguém. A realização desse ato está na própria vida cujas trocas simbólicas operam a inserção do indivíduo na coletividade. Tanto na educação familiar (informal) quanto na ação de um preceptor (formal) ou de uma escola (institucional), a afetividade atenua a agressão dos símbolos culturais e promove um elo entre as pessoas, proporcionando, dessa forma, um clima de prazer e divertimento:

Observai tão-somente, contra a opinião comum, que o governante de uma criança deve ser jovem e até tão jovem quanto pode ser um homem sensato. Gostaria que ele pudesse ser ele própria criança, se possível, que pudesse tornar-se o companheiro de seu aluno e angariar sua confiança partilhando seus divertimentos. (Rousseau, 1973, p. 28)

Ao contrário da imposição pedagógica dos jesuitas e de outros métodos educacionais, a obra rousseauniana sugere que uma educação interativa, espontânea, divertida, prática e contextualizada aperfeiçoa a natureza humana e promove a felicidade. Rousseau (1973) adverte que

Platão, em sua República, que acreditam tão austera, só educa as crianças com festas, jogos canções, passatempos: parece que fez tudo ensinando-lhes a se divertirem. (p. 97)

Sem imposição institucional, a ação formativa, iniciada pelos pais e possíveis preceptores, estende-se a toda a comunidade na medida em que a dinâmica da vida social imprime no educando a simplicidade, o respeito, o amor e a arte da convivência. Rousseau elege a vida campestre como o melhor local para o desenvolvimento dessas qualidades, tendo em vista a proximidade da natureza e de um mundo rústico, bem distante da corrupção da vida nas cidades. Diz ele: "Quanto a meu Emílio, eu o crio no campo e seu quarto nada terá que o distinga do de um camponês" (Rousseau, 1973, p. 79).

Além da simplicidade própria à vida rural, o campo, com sua realidade espaço-temporal bem distinta da agitada vida urbana, possibilita o desenvolvimento do quesito maior da formação humana: a liberdade. Proclama Rousseau (1973) em seu tratado educacional:

Preparai de longe o reinado de sua liberdade e o emprego de suas forças, deixando a seu corpo o hábito natural, pondo-a em estado de ser sempre senhora de si mesma e fazendo em tudo sua vontade logo que tenha uma. (p. 43)

E prossegue mais adiante: 
Quanto a meu aluno, ou melhor o da natureza, exercitado desde cedo a bastar-se a si mesmo na medida do possível, não se acostuma a recorrer sem cessar aos outros e menos ainda a exibir-lhe seu grande saber. Em compensação julga, prevê, raciocina em tudo que se relaciona de perto consigo. Não discursa, age: não sabe uma palavra do que se faz na sociedade, mas sabe muito bem o que lhe convém. Como sempre em movimento, é forçado a observar muitas coisas e a conhecer muitos efeitos; adquire rapidamente uma grande experiência; toma lições da natureza e não dos homens; e tanto mais bem se instrui, quanto não vê nenhuma intenção de instruí-lo. Assim, seu corpo e seu espírito se exercitam ao mesmo tempo. Agindo sempre segundo seu pensamento e não segundo o de outrem, une continuamente duas operações; quanto mais se faz forte e robusto, mais se torna sensato e judicioso. É o meio de ter um dia aquilo que julgam incompatível, e o que quase todos os grandes homens reuniram em si, a força do corpo e a da alma, a razão de um sábio e o vigor de um atleta. (p. 113)

Essa desnaturação programada e gradual a partir do campo opera-se por meio de uma semiologia do ordinário e do corriqueiro. Desde a faina doméstica ao árduo labor das colheitas, dos encontros casuais às festas comunitárias, tudo serve de instrumento para entender 0 conteúdo real do fenômeno humano e a dinâmica de suas trocas simbólicas. É por meio das festas camponesas, por exemplo, que se estabelece um espaço propício para as relações realmente afetivas, sinceras e justas onde a sensibilidade possa ser aguçada. Se no teatro alguém vive no nosso lugar e se apresenta num tablado acima de todos e para quem todas as atenções devem voltar, na festa popular, todos participam igualmente e se divertem em danças coletivas numa fusão completa de cores, gestos, faces, figuras e condição material, convergindo as atenções para si mesmos. Nela, o homem entra em contato direto com o próximo sem necessidade de máscara. Na simplicidade, sem luxo ou ostentação de riqueza, o homem é mais homem porque se libera do ego narcísico e da tirania do amor próprio. Como bem expõe Freitas (2003):

A criação coletiva em que se constitui a festa popular, estando alicerçada na participação comum, permite ao indivíduo experimentar por meio das sensações aquilo que no cotidiano não pode ser vivido. Ao mesmo tempo, ajuda a criar uma imagem de pessoa humana que define, senão os valores e os ideais de um grupo ou de uma civilização, ao menos a representação individualizada dos conflitos que concernem ao homem como tal. A festa contribui, assim, para esboçar o perfil de uma personalidade que se opõe àquela que emerge na vida cotidiana. Nela, o ideal propriamente político ganha uma figuração viva e concreta, na qual o prazer do convívio é elevado à sua máxima potência. Ela opera uma inversão na forma de se colocar no mundo e nos lembra que há outros pontos de vista, que é possivel projetar nossa existência a partir de outros lugares. Aqui a práxis coletiva adquire um novo sentido. (p. 45)

Um perfil que se opõe à vida cotidiana deteriorada, principalmente a vivenciada por Rousseau em Paris e outros centros urbanos, é certamente aquele que venha a ser fruto de uma educação da fuga, educação da negação da negação. No plano da infância, é a educação negativa pelo qual se evita que a crianças caiam nessa deterioração: "0 único hábito que se deve deixar a criança adquirir é o de não contrair nenhum" (Rousseau, 1973, p. 43). No plano geral de formação do homem, é a educação das necessidades. E tanto para as necessidades vitais como para as culturais é o campo o melhor local para estabelecer um contínuo contato com a natureza e se aproximar de sua pureza original. Base, portanto, da moral rousseauniana 
e do alicerce de toda educação, essa pureza serve de alicerce para o desenvolvimento da virtude e de elo entre a razão e a sensibilidade.

Derathé (1949) deixa claro que bondade e virtude são diferentes, porque enquanto a primeira é um dom da natureza, a outra deve ser uma conquista do próprio homem no âmbito de bem conduzir sua vontade e sua razão. “0 que é então um homem virtuoso?" pergunta Rousseau (1973). E responde: "É aquele que sabe dominar suas afeições, pois então segue sua razão, sua consciência, faz seu dever, mantém-se dentro da ordem e nada o pode afastar dela" (p. 525).

Por essa reflexão e pelas idéias contidas no discurso do vigário saboiano, podemos inferir que a virtude resulta do exercício da razão, guiada pela consciência moral e substanciada na sensibilidade, cuja base não é outra senão a bondade natural. Encadeamento que combina a ação da natureza e a ação do homem, iniciando pela contemplação de um ser supremo. Se o espiritualismo do vigário aparentemente sujeita a moral à metafísica, na verdade o que faz é o contrário. Segundo Derathé (1949), “a solidariedade que Rousseau estabelece entre a moral e a religião acaba, no final, prejudicando a religião; pois Rousseau elimina da religião tudo o que não é indispensável à vida moral" (p. 172). Tanto que seus preceitos podem ser entendidos como o credo de uma religião natural, quase animista, cuja essência reside numa harmonia universal dos homens consigo mesmos e com a ordem imaterial que move o universo, independente se é um ser pessoal ou uma força cósmica criadora. 0 Deus de Rousseau seria mais um guia da consciência, uma voz interior, a sussurrar os ditames e os desígnios da Natureza.

Tendo em vista que a consciência é, para Rousseau, a voz da alma e as paixões, a voz do corpo, é imprescindível a existência de uma religião no conteúdo da formação do homem. Considerando até mesmo seu sentido etimológico, do latim re ligare, o termo serve bem para o propósito rousseauniano que é o de reencontro do homem com sua unidade perdida, com sua di- mensão deteriorada e sua natureza original. Portanto, a religião é vista como uma instituição que auxilia grandemente no processo de desnaturação, desenvolvendo no homem a bondade, a misericórdia, o respeito, o amor e, como prêmio, a felicidade suprema.

A metafísica de Rousseau é, ao mesmo tempo, uma recusa do materialismo ateu bem como do fanatismo religioso. Sua posição mediana procura evitar o extremismo de ambos os lados e busca a verdade nas relações sensuais do mundo empírico e no compromisso moral de uns para com os outros. É a tentativa de guiar o aperfeiçoamento humano reconciliando a natureza e a cultura numa espécie de retorno ao paraíso perdido sem se despojar dos atributos da ciência e da reflexão. Sem deixar o tom pedagógico, o vigário saboiano encerra suas palavras dizendo ao seu ouvinte:

Ousai proclamar Deus entre os filósofos; ousai pregar a humanidade aos intolerantes. Talvez sejais o único de vosso partido; mas levareis convosco um testemunho que vos dispensará do dos homens. Que vos amem ou vos detestem, que leiam ou desprezem vossos escritos pouco importa. Dizei o que é verdade, fazei o que é bem; o que importa ao homem é cumprir seus deveres na terra; e é se esquecendo que se trabalha para si. Meu filho, o interesse particular nos engana; só a esperança do justo não engana. (Rousseau, 1973, p. 361; grifos meus)

0 personagem místico do romance Emílio é, por assim dizer, um apóstolo da religião do homem. Credo universal que dispensa as revelações, os dogmas, o aparato cerimonial e todo o jogo de aparência para defender uma comunicação individual do ser humano com a Divindade por meio do sentimento interior. A consciência tende a seguir a ordem da Natureza e não há melhor guia para os assuntos de interesses imediatos e reais até porque ela fala direto ao coração. Fala das verdades eternas que se re- 
sumem no amor à humanidade, à liberdade, à justiça e ao belo moral (Rousseau, 1973).

A educação não pode negligenciar o fato de que honrar e amar o autor da espécie e o ser que a protege é uma conseqüência natural do amor a si nem deve esquecer que a liberdade precisa ser orientada para que não haja abuso do livre arbítrio e que suas faculdades sejam canalizadas para o uso das boas ações: "Ocupai vosso aluno com todas as boas ações a seu alcance” (Rousseau, 1973, p. 280).

A prédica rousseauniana rejeita as idéias absolutas e abstratas em favor das luzes naturais que manifestam na interioridade humana e guiam a elaboração de máximas para uma boa conduta na terra. As fontes não são livros filosóficos ou sagrados, mas o próprio coração que possui as regras "escritas pela natureza em caracteres indeléveis” (Rousseau, 1973, p. 325), que servem de elementos litúrgicos para esse culto ao homem interior, ao homem natural, sendo, portanto, máximas morais para realização do ser humano em sua plenitude, em sua totalidade. Desse modo, se bem preparado nas coisas humanas, cheio de sentimentos naturais, estará vacinado contra as vicissitudes do amour propre e do domínio das paixões deterioradas.

Analisando tudo isso, podemos ter a sensação de que Rousseau defende uma espécie de pedagogia da ignorância ou do desconhecimento. No entanto, sua perspectiva não é a do regresso a um estado primitivo e tosco que limita o homem às ações do instinto. Seu estilo enfático e exaltado depõe contra os livros e todo um saber já instituído, mas, no fundo, ele sabe que o processo deve ser conduzido por um exercício essencialmente racional e intelectual: somente a razão nos ensina a conhecer o bem e o mal. A consciência que nos faz amar um e odiar o outro, embora independente da razão, não pode pois desenvolverse sem ela. (Rousseau, 1973, p. 48)

A singularidade de seu discurso é que ratio e divinatio convergem politicamente para a afirmação do homem tanto no âmbito do discurso, isto é, da universalidade, quanto nas diversas situações da vida prática que ocorrem no seio da organização social. As disposições físicas e metafísicas são instrumentais. A cultura e o artifício devem almejar a realização plena da natureza humana. É essa a principal lição que o Emílio deixou como contraponto à velha cantoria-solo da escolástica, bem como à polifonia do mundo moderno. Lição paradoxal não apenas às trevas e às luzes, mas também a toda a modernidade até nossos dias, cuja arte ainda prima pela aparência, pela dissimulação e, o que é pior, pela objetivação e coisificação do ser. A formação do homem tal qual Rousseau concebeu no Emilio tem muito a ver com as aspirações da UNESCO em seu projeto educacional para o século XXI.

Obviamente lidamos hoje com um mundo bem mais complexo que o vivenciado por Rousseau. No entanto, sua abordagem continua atual e rica em significados para repensarmos os processos de formação não como atos formais e mecânicos que devem ser levados a termo por uma exigência institucional. Educar é construir sentidos para a própria existência humana. Assim, evidenciar a dimensão natural do ser humano nas teias e tramas do aprender e ensinar (Brandão, 2001) é o desafio e, ao mesmo tempo, o estímulo que se coloca à educação dos nossos dias. E para isso, o Emílio é fonte quase inesgotável para nossas reflexões e nossas ações. 


\section{Referências bibliográficas}

BRANDÃO, C. R. Sobre teias e tramas de aprender e ensinar. Inter-Ação: Revista da Faculdade de Educação da UFG.Goiânia: Editora da UFG, v. 1,n. 1, 1975.

CERVANTES, M. de. El ingenioso hidalgo Don Quijote de La Mancha. 39 ed. Madrid: Espasa-Calpe, 1993.

COSTA, M. V. (Org.). Escola básica na virada do século: cultura, política e currículo. 2 ed. São Paulo: Cortez, 2000.

DEFOE, D. Robinson Crusoé. São Paulo; Rio de Janeiro; Porto Alegre: W. M. Jackson Inc., 1947. (Coleção Grandes Romances Universais, v. 1).

DELORS, J. Educação: um tesouro a descobrir. Relatório para a UNESCO da Comissão Internacional sobre Educação para o século XXI. 8 ed. São Paulo: Cortez; Brasília: MEC/UNESCO, 2003.

DERATHÉ, R. Les rapports de la morale et de la religion chez Jean-Jacques Rousseau. Paris: Revue Philosophique, 1949, p. 143-173.

FREIRE, P. Pedagogia da indignação: cartas pedagógicas e outros escritos. São Paulo: Ed. Unesp, 2000.

FREITAS, J. de. Política e festa popular em Rousseau: a recusa da representação. São Paulo: Humanitas/FFLCH/USP; Fapesp, 2003.

GADOTTI, M. Os mestres de Rousseau. São Paulo: Cortez, 2004.

NUNES, B. Introdução à filosofia da arte. 5 ed. São Paulo: Ática, 2000.

PAIVA, W. A. de P. 0 Emílio e a formação do cidadão do mundo moderno. 2005. Dissertação (Mestrado)- Faculdade de Ciências Humanas e Filosofia da Universidade Federal de Goiás. Goiânia, 2005.

ROUSSEAU, J.-J. As confissões. v. 2. Trad. Rachel de Queiroz. 2 ed. São Paulo: Atena, 1959.

Oeuvres complètes. v. 4. Paris: Gallimard, 1964. (Bibliothéque de la Plêiade).

Emílio ou da educação. 2 ed. São Paulo: Difusão Européia do Livro, 1973.

Projeto para a educação do Senhor de Sainte-Marie. Edição bilíngüe (francês e português). Trad. Dorothée de Bruchard.

Porto Alegre: Paraula, 1994.

STAROBINSKI, J. The invention of liberty. New York: Rizzoli International, 1987.

STRECK, D. R. Educação para um novo contrato social. Petrópolis: Vozes, 2003.

Recebido em 24.11.05

Aprovado em 05.03.07

Wilson Alves de Paiva, pedagogo pela UFPA, mestre em filosofia pela UFG e doutorando em Filosofia da Educação pela USP, é professor da Faculdade de Educação da UFG, atua na área de Filosofia, Política Educacional e História da Educação, foi assessor técnico da (SEDUC/PA) e secretário municipal de Educação do município de Trairão/PA. 